\title{
Os Manuscritos de Qumran ou do Mar Morto
}

\author{
The Qumran Manuscripts or Dead Sea Manuscripts
}

\begin{abstract}
Ildo Perondi
Mestre em Teologia Bíblica pela Universidade Urbaniana de Roma, professor de Sagradas Escrituras e Ecumenismo na Pontifícia Universidade Católica do Paraná (PUCPR), Câmpus Londrina, Coordenador do Curso de Pós-Graduação em Teologia Bíblica, Londrina, PR - Brasil, e-mail: ildo.perondi@pucpr.br
\end{abstract}

\section{Resumo}

Na primavera de 1947 foram encontrados os primeiros manuscritos em Qumran. Essa foi considerada a maior descoberta de manuscritos da época moderna e a mais importante na região da Terra Santa. É certo que foi uma riqueza, mas também provocou algumas polêmicas. Neste artigo procuraremos apresentar de forma resumida o que são os Manuscritos de Qumran ou do Mar Morto, a sua história, as controvérsias em torno da sua publicação e a ajuda que trouxeram para a tradução e interpretação dos livros do Antigo Testamento. Abordaremos também a influência que eles proporcionaram para uma melhor compreensão de muitos elementos do judaísmo da época de Jesus e a incidência que as ideias da comunidade que viveu em Qumran tiveram na formação do Novo Testamento e do cristianismo.

Palavras-chave: Manuscritos. Qumran. Mar Morto. Bíblia. Cristianismo. 


\section{Abstract}

In the spring of 1947, there were found the first Manuscripts at Qumran. They were considered the highest finding of manuscripts in the modern era and the most important in the Holy Land. Despite of being considered a wealth, they also lighted up some polemics. In this article, it is briefly presented what the Qumran Manuscripts (or Dead Sea Manuscripts) are, as well as their history, the controversies around their publication and the help brought by them to the translation and interpretation of Old Testament books. It will also be approached the influence that they had to a better comprehension of many elements of Judaism from Jesus ages and the incidence of the ideas from the community that lived in Qumran under the formation of the New Testament and Christianism.

Keywords: Manuscripts. Qumran. Dead Sea. Bible. Christianism.

\section{Introdução}

Os Manuscritos de Qumran ou do Mar Morto foram a maior descoberta científica do milênio passado para o estudo da Bíblia, tanto pela quantidade como pela qualidade dos escritos. Com isso, tivemos acesso a informações sobre uma comunidade marginal ao judaísmo da época das origens do cristianismo. Nas grutas foram encontrados textos de todo o Antigo Testamento (à exceção do livro do Esther), o que ajudou muito nas traduções da Bíblia. Para se ter uma ideia, até a metade do século passado, trabalhava-se sobre códigos que eram do ano 1008 d.C, já os manuscritos são da época de Jesus ou até anteriores. Não foram encontrados textos do Novo Testamento, mas o conhecimento da comunidade que vivia em Qumran veio confirmar muitos dados contidos no Novo Testamento. É certo que hoje existe muita especulação, nem sempre bem fundamentada, sobre os manuscritos e que certos artigos causam confusão ou visam ao sensacionalismo.

No segundo semestre de 2004, alguns desses manuscritos e objetos estiveram expostos no Rio de Janeiro e depois em São Paulo. Ultimamente 
encontramos livros, publicações e reportagens muito boas em jornais, revistas e sites na internet, porém, surgiram também algumas publicações sensacionalistas e livros best sellers (como os de M. Baigent e R. Leigh) ou o recente livro O código Da Vinci, de Dan Brown. Esse tipo de publicação mais confunde que informa, pois são obras de amadores, ignorando todo o trabalho feito e esquecendo a contribuição e o bem que esses manuscritos nos trouxeram.

Abordaremos a seguir os fatos e pontos principais dessa descoberta, e algumas das polêmicas decorrentes, sem pretender esgotar a importância e a complexidade que os Manuscritos de Qumran ou do Mar Morto significaram para a tradução da Bíblia e para o cristianismo.

\section{Qumran}

É o nome do lugar onde foram encontrados os primeiros manuscritos numa gruta. Situa-se perto do Mar Morto, em Israel. Em seguida foram encontradas outras grutas com outros manuscritos e objetos, não só em Qumran, mas em toda a região do Mar Morto, e por isso hoje se fala dos Manuscritos de Qumran ou do Mar Morto (ou do Deserto de Judá). Foram localizados também os restos das construções onde se reunia a comunidade.

Nos últimos dois milênios de história, a região passou por diversas dominações políticas. No ano 70 d.C., os romanos destruíram o Templo e a cidade de Jerusalém, e Israel deixou de existir enquanto Estado judaico. Em seguida, os romanos conquistaram e destruíram a comunidade de Qumran e depois tomaram a fortaleza de Massada, localizada próximo a Qumran. E em 135 d.C. foi vencida a última resistência judaica.

Após a dominação romana, sucessivas potências ocuparam esse território. $\mathrm{Na}$ época em que se descobriram os primeiros manuscritos a região estava sob dominação inglesa, em seguida o território passou a fazer parte da Jordânia. Em 1948 Israel tornou-se um Estado independente, porém, somente em 1967, com a guerra dos seis dias, é que a região de Qumran e do Mar Morto passou a fazer parte do território de Israel. 


\section{0 que são os manuscritos?}

Os manuscritos que foram encontrados nas onze grutas são escritos, em couro ou papiros, em sua maioria na língua hebraica e alguns poucos em aramaico ou grego. Alguns estavam em bom estado e outros estavam bastante deteriorados com o tempo e as condições em que foram guardados. Ao todo foram encontrados em torno de 800 documentos. Alguns estudiosos sugerem que alguns manuscritos sejam rolos de livros sagrados que os judeus do Templo esconderam ali quando pressentiram que os romanos destruiriam o Templo e a cidade de Jerusalém. Alguns são apenas fragmentos (pedaços) de textos. Em geral, podemos dizer que os manuscritos encontrados se classificam assim:

a) Manuscritos Bíblicos: esses textos são cópias fiéis, que os habitantes da região de Qumran (escribas) transcreveram dos livros do Antigo Testamento (cerca de 225 manuscritos). O Livro dos Salmos é o de que foi encontrado maior número de cópias; o segundo é o Deuteronômio; e o terceiro é Isaías (curiosamente são também esses os três livros mais citados pelo NT). Somente dos livros de Ester e Neemias não foi encontrada nenhuma cópia.

Relação dos manuscritos de livros bíblicos encontrados:

$\begin{array}{lllr}\text { Gênesis } & 15 & \text { Salmos } & 36 \\ \text { Êxodo } & 17 & \text { Provérbios } & 2 \\ \text { Levítico } & 13 & \text { Jó } & 4 \\ \text { Números } & 8 & \text { Cântico dos Cânticos } & 4 \\ \text { Deuteronômio } & 29 & \text { Rute } & 4 \\ \text { Josué } & 2 & \text { Lamentações } & 4 \\ \text { Juízes } & 3 & \text { Eclesiastes } & 3 \\ \text { 1-2 Samuel } & 4 & \text { Ester } & 0 \\ \text { 1-2 Reis } & 3 & \text { Daniel } & 8 \\ \text { Isaías } & 21 & \text { Esdras } & 1 \\ \text { Jeremias } & 6 & \text { Neemias } & 0 \\ \text { Ezequiel } & 6 & \text { 1-2 Crônicas } & 1 \\ \text { 12 Profetas } & 8 & & \end{array}$


Também foram encontradas cópias de alguns livros deuterocanônicos que não vieram a fazer parte da Bíblia Hebraica: Tobias (quatro cópias em aramaico e uma em hebraico); Eclesiástico (alguns fragmentos); Carta de Jeremias = Baruc 6 (foi encontrada uma cópia em grego); Salmo 151, que se encontra na LXX (uma cópia).

b) Apócrifos: foram encontradas cópias de diversos livros que não entraram no cânon da Bíblia Hebraica, exemplo: Apócrifo do Gênesis, de Henoc, de Noé, de Lamec, do Livro dos Jubileus, etc. É bom lembrar que, na época em que foram escritos os manuscritos, a lista (cânon) dos livros do AT ainda não havia sido concluída, embora já houvesse certo consenso.

c) Comentários Bíblicos: foram encontrados muitos textos que eram comentários e interpretações que a comunidade escreveu sobre os livros do AT. Esses comentários são importantes para percebermos como uma comunidade judaica daquele tempo interpretava os textos sagrados. Também foram encontradas muitas cópias de targums e midraxes rabínicos (estudos e interpretações).

d) Livros da Comunidade: a comunidade também escreveu livros sobre a sua vida. São textos legais sobre a organização da comunidade, livros e textos litúrgicos, poéticos, apocalípticos, escatológicos, comerciais, etc. Os mais famosos são: Regra da Comunidade, Rolo do Templo, Documento de Damasco, Carta Halákica, Regra da Guerra, etc. Foi encontrado também um famoso Rolo de Cobre - um livro escrito em cobre. Trata-se de um enigma, pois contém o mapa de onde estão escondidos cerca de 60 tesouros (mais de 200 toneladas de ouro e prata), mas parece ser uma fantasia e jamais se encontrou qualquer vestígio desse suposto tesouro.

Além dos manuscritos, foi encontrada ainda uma grande quantidade de outros materiais importantes para o conhecimento da comunidade, como: cerâmicas, moedas, objetos de trabalho, vestuários, calçados, utensílios de cozinha e de trabalho, etc.

A data em que foram escritos os manuscritos gerou certa controvérsia. A hipótese de que sejam uma farsa hoje está descartada, pois foram 
submetidos à análise com os métodos mais modernos, como o carbono 14 , e hoje cientificamente se pode afirmar que os mais antigos foram escritos no século III a.C. e os mais tardios depois do ano 68 d.C.

\section{Como foi a descoberta dos manuscritos}

Essa grande descoberta iniciou com um fato ingênuo e, na sequência, teve uma longa história (MARTINEZ, 1995, p. 20-21; VANDERKAM, 1997, p. 12-24). Na primavera de 1947, três beduínos da tribo Ta'amireh, que cuidavam do seu rebanho na região de Qumran, divertiam-se jogando pedras dentro das grutas. Um deles, porém, sentiu um som estranho. Ele voltou sozinho de madrugada e descobriu, entre outras coisas, um vaso contendo manuscritos antigos. Os beduínos tentaram vendê-los quase sem sucesso.

Outra versão indica que um beduíno foi em busca de uma cabra perdida, que se havia refugiado em uma das grutas, e fez as primeiras descobertas. O certo é que os beduínos chegaram a um senhor chamado Kando, que se converteu no intermediário para passar adiante os materiais descobertos. Como pensavam que eram escritos em siríaco, os beduínos foram encaminhados ao metropolita Mar Athanasius em Jerusalém, da Igreja Siro-Jacobita (interessante que o porteiro vendo aqueles beduínos mal vestidos quase colocou tudo a perder, mandando-os embora!). O metropolita comprou os manuscritos por cerca de 100 dólares (tempos depois os vendeu nos Estados Unidos por 250.000 dólares!).

O metropolita consultou Sukenik, um professor da Universidade Hebraica de Jerusalém. A partir disso, iniciou-se uma longa história em que a descoberta foi levada a sério. Os beduínos conseguiram novos manuscritos, mas, em razão da situação de conflito na região, alguns desses manuscritos foram levados aos Estados Unidos. Iniciaram-se também escavações e novas buscas na região, coordenadas por G. L. Harding (jordaniano) e pelo Pe. Roland de Vaux, da Escola Bíblica de Jerusalém, que escavaram e estudaram o local, fazendo um estudo da comunidade e, em várias expedições, fazendo novas descobertas. Contudo, os beduínos, lembrando que seus avós contavam a história de um caçador que havia seguido uma lebre numa gruta, foram de novo os protagonistas e descobriram 
outras duas grutas (chamadas Gruta 4), onde foi encontrado o maior e melhor número de material, que era o resto da Biblioteca Central da comunidade de Qumran.

Em Jerusalém foi construído um local especial para colocar e proteger todo esse material, o chamado "Santuário do Livro", em forma de tampa de um jarro, semelhante àquele em que foram encontrados os primeiros manuscritos. É onde hoje se encontra todo o material, estando sob a custódia do Museu de Jerusalém, hoje administrado pelo Estado de Israel. Os pesquisadores suspeitam que cerca de quatro rolos estão desaparecidos ou se perderam para sempre.

\section{A comunidade de Qumran}

A descoberta dos manuscritos gerou curiosidade sobre quem teriam sido os habitantes que viveram nessa região. Biblistas da Escola Bíblica de Jerusalém, liderados por R. de Vaux, estudaram essa comunidade que viveu ali e produziu todo esse material. Eles se basearam nos resultados das escavações e também em historiadores antigos, como Plínio, o Velho, Fílon e Flávio Josefo. A conclusão foi que a comunidade começou a ser povoada cerca de 700 anos antes de Cristo. Contudo, somente uns 200 anos a.C. é que teve a organização como grupo de essênios, um grupo que se separou da comunidade judaica para viver mais radicalmente a sua fé. Essa comunidade sofreu uma forte destruição com o terremoto de 31 a.C. e depois deve ter ressurgido, até ser destruída pelos romanos e ter seu fim por volta dos anos 100 d.C.

Podemos descrever alguns traços dessa comunidade:

a) seus membros tinham uma forte vida comunitária, com normas para a admissão, formação e vivência interna. Seguiam uma disciplina rígida, rezavam e faziam penitência, tinham os bens praticamente em comum. Eles liam, interpretavam e davam muita importância às Escrituras. Esperavam o fim dos tempos, em que eles, os "filhos das luzes", combateriam ao lado de Deus contra os "filhos das trevas";

b) a princípio parece que era uma comunidade constituída somente de homens, porém, nos cemitérios foram descobertas ossadas também 
de mulheres (que podiam ser de visitantes ou familiares que viviam nas proximidades);

c) uma figura importante na comunidade era o Mestre da Justiça;

d) na comunidade havia uma forte expectativa messiânica, porém, eram dois os Messias esperados: um de linha mais política, que seria o descendente de David, e o segundo seria o Messias Sacerdote, descendente de Aarão;

e) seguiam um calendário lunar que era de 364 dias.

O mais provável é que essa comunidade fosse um grupo de essênios, em um grupo de mais ou menos 200 pessoas que residiam no local, porém, seu número deve ser variado em diferentes fases da sua história.

Ultimamente a tese sobre a existência dos essênios foi colocada em dúvida, sobretudo pela professora Rachel Elior, da Universidade Hebraica de Jerusalém, especializada em mística judaica, afirmando que os essênios são uma invenção de Flávio Josefo e que eles nunca existiram. Ela explica que os manuscritos do Mar Morto, por sua vez, foram redigidos por saduceus de Jerusalém e guardados nas grutas de Qumran.

No II Simpósio Internacional de Teologia da PUC-Rio, realizado de 31 de março a 02 de abril de 2009, estava presente Florentino Garcia Martinez, uma das maiores autoridades sobre esses manuscritos. Questionado sobre as opiniões de Rachel Elior, mostrou-se bastante cético sobre suas teorias, pois é muito fraca a hipótese de que tenham sido escritos pelos saduceus (que tinham por inspirados somente os livros do Pentateuco). A tese de Elior não explica os escritos próprios da comunidade e muito menos quem teria sido a comunidade que deixou sinais muito concretos no local.

\section{O Novo Testamento e Qumran}

Após as primeiras descobertas, surgiram várias hipóteses indicando que alguns dos personagens do NT seriam provenientes de Qumran ou tiveram contatos com essa comunidade. De fato, quem visita hoje Qumran, na recepção, pode assistir a um vídeo sobre a comunidade e a importância 
dos manuscritos encontrados. O vídeo menciona um personagem que esteve em Qumran, mas que foi expulso por não se adaptar às exigências da comunidade. Esse personagem é identificado como o profeta João Batista. E se lermos os evangelhos sinóticos veremos que os traços de João Batista e a radicalidade da sua proposta têm muito a ver com a comunidade de Qumran. Outros sugerem que Tiago, "irmão do Senhor", (cf. At 12,17; 15,13; Gl 1,19, etc.) pudesse ter ligações com a comunidade. Robert Eisenman até chegou a afirmar que esse Tiago seria o Mestre da Justiça da comunidade. Nesses textos se falaria dos primeiros cristãos e, em particular, emergiria na sua plena luz o contraste que dividia a corrente de Tiago e aquela de Paulo (EISENMAN; WISE, 1994, p. 11). As hipóteses indicando que o apóstolo Paulo viesse dessa Comunidade devem ser descartadas, já que o próprio apóstolo Paulo várias vezes afirma seu passado como fariseu e nunca como essênio.

É interessante ver o paralelismo de certos termos com os escritos do Novo Testamento. Um dos vocábulos que mais chamou a atenção é "os muitos" ou "maioria" que encontramos em At 15,12 e em 2Cor 2,5-6 e no relato da Eucaristia de Mt 26,27-28; Mc 14,23-24 e Lc 22,20. Em Qumran foi usado o mesmo termo seja em relatos jurídicos e celebrativos. Encontramos também outras expressões, como: "justiça de Deus", "pobres em espírito", "obras da lei”, "Igreja/Assembleia de Deus”, "a sorte dos santos", "o Senhor do céu e da terra”, etc., que não são encontradas nos textos rabínicos da época.

Textos como 2Ts 2,7 "o mistério da iniquidade"; o tema paulino da "justificação pela fé" (cf. Rm 3,21-24; Gl 2,16); a figura de Melquisedec, lembrada na Carta aos Hebreus; a expressão "ele será chamado Filho de Deus" de Lc 1,35-37; entre outros, também são encontrados nos manuscritos.

No entanto, se existem paralelos, encontramos também divergências. Segundo o Dicionário bíblico (McKENZIE, 1984, p. 766-767), E. Stauffer enumera pelo menos oito pontos diferentes entre a comunidade de Qumran e as primeiras comunidades cristãs:

1) um clericalismo maior em Qumran;

2) mais ritualismo e cerimônias;

3) o preceito de amar os filhos da luz e odiar os filhos das trevas; 
4) o militarismo e a preparação para a guerra "apocalíptica";

5) a supervalorização do calendário;

6) o caráter esotérico;

7) a expectativa dos dois Messias;

8) o relacionamento diverso com o Templo, com os sacerdotes de Jerusalém e com a Lei.

\section{Problemas com a publicação dos manuscritos}

No início, a equipe responsável pelo cuidado dos manuscritos e pela sua divulgação e publicação era constituída de um pequeno grupo chefiado por Roland de Vaux, da Escola Bíblica de Jerusalém. Devemos recordar que muitos fatores atrapalharam o trabalho. Basta lembrar que o território passou por mudanças políticas importantes: Inglaterra, Jordânia e depois Israel. Houve dificuldade de recursos econômicos e mesmo humanos (pessoas capazes de traduzir e interpretar os documentos). Falta de recursos para a aquisição dos manuscritos. Tudo isso fez com que, passados 40 anos das primeiras descobertas, muitos textos ainda não fossem de conhecimento público. Surgiram suspeitas sobre as descobertas e sobre os seus conteúdos, falou-se até em conspiração. Mesmo entre os biblistas católicos e protestantes criou-se um mal-estar, qualificando como um "escândalo" essa demora. Era inadmissível que documentos assim importantes ficassem em segredo, praticamente sem nenhuma razão, e que não fossem de domínio público.

É certo que por causa da falta de recursos - financeiros e humanos e da morte de R. de Vaux (que foi substituído por J. Strugnell - inglês, presbiteriano e depois católico - já velho) houve atraso nas traduções e publicações. Além disso, a equipe queria publicar os textos com uma interpretação que fosse unânime entre os diversos membros. Tudo isso deu margem a inúmeras especulações.

Por isso, na década de 1990 houve uma mudança na equipe, mais recursos e pessoas foram colocados à disposição e assim hoje todos os manuscritos já foram divulgados, pelo menos por meio de fotografias. Hoje, todos os textos já estão publicados e traduzidos, por meio da Discoveries in the Judaean Desert, da Oxford University Press, que é a publicação oficial dos manuscritos, 
já com mais de 40 volumes. Em português, temos a excelente obra Textos de Qumran, de Florentino Garcia Martinez, traduzida por Valmor da Silva, pela Editora Vozes, em 1995, que traz praticamente todos os textos já publicados.

\section{Questões e polêmicas com o cristianismo}

É certo que documentos dessa importância e que têm algo a dizer sobre a própria comunidade de Qumran, mas também sobre o judaísmo, o cristianismo e a própria cultura mundial, tendem a causar polêmicas e divergências. Vejamos as principais (VANDERKAM, 1997, p. 204-220):

a) John Allegro: entre os membros da equipe havia um pesquisador chamado John Allegro, inglês agnóstico. Graças a divergências com o grupo, ele se retirou fazendo fortes acusações, dizendo que a equipe estava escondendo documentos da Gruta 4. Segundo ele, havia manuscritos que poderiam prejudicar o cristianismo e havia uma conspiração do Vaticano para impedir a divulgação destes. Ele mesmo se pôs a publicar manuscritos por conta, que depois se revelaram de péssima qualidade (Strugnell fez cerca de cem páginas de notas de correções ao seu livro). Allegro atribui as origens do cristianismo aos efeitos de um alucinógeno. Quase na mesma direção está a interpretação de Bárbara A. Thiering, que vê João Batista como o Mestre da Justiça e Jesus como o Sacerdote Ímpio.

b) Textos do Novo Testamento em Qumran?: J. O'Callaghan, jesuíta espanhol, insistiu, nos anos 1970, que havia descoberto partes de textos do Novo Testamento em Qumran, na gruta 7 (nessa gruta foram descobertos também textos escritos em grego). Segundo ele, seriam textos de Marcos, Atos dos Apóstolos, Romanos, Primeira Timóteo, Tiago e Segunda Pedro. Essa hipótese foi assumida também pelo alemão $C$. Thiede e fez sucesso, mas também logo foi contestada (VANDERKAM, 1997, p. 181). Primeiro, porque a grafia não é tão igual; segundo, porque a Segunda Carta de Pedro é colocada pela maioria dos biblistas como o último escrito do NT (portanto, foi escrita depois da destruição de Qumran); terceiro, porque não foi 
encontrado nenhum livro do NT, mas somente alguns fragmentos com textos parecidos; quarto, porque o material é muito fragmentado e não permite nenhuma hipótese segura. O texto encontrado (7Q5), e que O'Callaghan supõe seja de Mc 6,52-53, pode ser traduzido assim: "porque [não] haviam compreendido o fato dos pães estando o seu coração endurecido. Terminada a travessia chegaram ao território de Genesaré e chegaram à terra. Apenas desceram". $\mathrm{O}$ texto não fala de Jesus e poderia muito bem se referir a um outro fato, com outro grupo, ainda que se pareça com o texto de Marcos. Por isso, hoje se exclui a possibilidade que qualquer uma das onze grutas contenha algum texto da literatura cristã primitiva.

c) Jesus era de origem essênia?: alguns autores procuram comparar as práticas, os costumes e as propostas entre Jesus e as primeiras comunidades cristãs com os essênios e descobrem muitas semelhanças. Por isso, afirmam que o cristianismo seria de origem essênia. Essa hipótese também é fraca, pois temos todos os textos do NT que comprovam a origem judaica de Jesus na Galileia. Embora com isso não se negue que alguns membros do grupo de Jesus (João Batista e alguns discípulos) possam ter tido ligações com a comunidade de Qumran.

d) O caso do Messias assassinado ou que assassinou: um dos textos que mais causou polêmicas foi 4 Q285. O fragmento estava em certa parte corrompido e foi passível de várias interpretações, por isso não foi logo divulgado. Isso ajudou a aumentar as suspeitas. Os estudiosos sugerem várias traduções: "e esses assassinaram (ou: assassinarão) o príncipe da comunidade, o reben[to de Davi]". O texto pode ser interpretado tanto no passado como no futuro. Outros preferem: "o príncipe da comunidade o matará (ou: o matou)". Poderia também ser: "o príncipe da comunidade, o rebento de Davi, o matará" ou: “matará o ímpio". Tudo isso traz certo paralelo com o NT. Em 1991, R. Eisenman publicou um livro (à revelia do comitê e desrespeitando até os direitos autorais) onde diz revelar textos inéditos, um dos quais falava da execução capital de um Messias e insiste que este seja Jesus e que por isso o texto não havia sido tornado público. Poucos são os que aceitam essa hipótese, já que Eisenman optou pela tradução menos segura. Em 1992, ele publicou outro livro 
juntamente com M. Wise. Contudo, em seguida, Wise se retratou das interpretações feitas, como se pode ver na apresentação da edição italiana feita por E. Jucci (EISENMAN; WISE, 1994, p. VII-XVI). No entanto, essas publicações tiveram o mérito de tornar públicos muitos dos manuscritos que demoravam em serem publicados.

Sobre os pontos acima, é bom lembrar que eminentes estudiosos encarregados da publicação dos manuscritos sempre afirmaram que, embora se encontrem muitos paralelos, não existe nada nos textos que tenha ligação direta com o nascimento do cristianismo na Galileia. Também em nenhum dos textos se encontra o nome de Jesus. As últimas análises dos manuscritos, feitas com carbono 14, comprovam que estes são anteriores ao cristianismo e, portanto, excluem definitivamente as teorias de uma origem zelota ou judeu-cristã dos manuscritos.

O que percebemos é que alguns (como O'Callaghan) gostariam de ver em Qumran e nos manuscritos os indícios de Jesus e dos textos do Novo Testamento. Não precisamos disso para a credibilidade da nossa fé. Outros, em outro extremo, querem fazer "provocações" e sugerir que Jesus e o cristianismo tenham origens essênias. Nem isso está nos manuscritos. Jesus continua sendo de origem judaica e o cristianismo continua com sua origem na Galileia.

Embora seja verdade que o pensamento de Jesus algumas vezes se aproximava das ideias dos essênios, porém, a prática de Jesus e das primeiras comunidades se distanciava muito do extremismo deles.

\section{Os manuscritos revelam informações que contrariam dogmas cristãos?}

Não. Os dogmas cristãos foram desenvolvidos no decorrer da história da Igreja, a partir das revelações do NT e também das reflexões teológicas posteriores. O cristianismo possui uma proposta própria, com formulações baseadas nas revelações bíblicas e em Jesus de Nazaré. É certo que podemos encontrar semelhanças entre aquilo que pensavam os habitantes de Qumran, mas podemos encontrar algumas analogias semelhantes também lendo outros escritos judaicos ou apócrifos da época. O judaísmo, o cristianismo e o 
islamismo podem aprender muito com as descobertas de Qumran, mas cada uma dessas religiões possui seus fundamentos próprios, cada uma das religiões fez e continua fazendo sua própria caminhada. Ora, se as revelações dos manuscritos contrariam os dogmas cristãos, é sinal que o Cristianismo não é dependente de Qumran e sim de outras fontes de revelações.

\section{A importância dos manuscritos}

Os Manuscritos de Qumran ou do Mar Morto foram, sem dúvida, a maior descoberta do milênio passado para a crítica literária e para o estudo da Bíblia, pois voltamos a ter acesso a cópias de textos bíblicos da época de Cristo e alguns até dos séculos II-III a.C. Tanto a religião judaica como o cristianismo, foram duas religiões muito perseguidas na história, por isso foi difícil preservar os originais ou cópias antigas dos textos sagrados. Para se ter uma ideia, antes dessa descoberta tínhamos a Bíblia Hebraica de Soncino, do ano 1477; a Bíblia Rabínica (com massora, isto é, anotações que os escribas faziam nas margens das páginas copiadas) de 1518, já impressa com a descoberta de Gutenberg; e a obra de Jacob Ben Chayyion, o famoso textus recceptus, de 1524/1525. Em 1929 surgiu a BHS, a Bíblia Hebraica de Kittel e P. Kahle, baseada no Código de Leningrado de 1008. Então, esses Manuscritos de Qumran ou do Mar Morto nos forneceram cópias aproximadamente mil anos mais antigas dos livros do Antigo Testamento. Tudo isso ajudou a corrigir e melhorar as traduções da Bíblia.

Para o mundo judaico, além da contribuição bíblica, a descoberta abriu o caminho para o acesso a manuscritos e materiais de dois mil anos, bem como às escavações e ao conhecimento de uma comunidade de um grupo judaico (os essênios), o que contribui também para entender melhor a história dos últimos anos da existência do Estado de Israel (antes de ser destruído pelos romanos). Proporcionou, também, um grande conhecimento da literatura hebraica pré-cristã.

Para o cristianismo, a maior importância está nas descobertas bíblicas e, também, em poder conhecer melhor o ambiente, as estruturas, ideias do mundo judaico da época de Jesus e de uma comunidade que tinha pontos em comum e pontos divergentes com o cristianismo: 
sustentando que o Jesus histórico era o Messias, no itinerário que conduziu à época escatológica, os cristãos se colocaram muito além em comparação com os essênios de Qumran, os quais esperavam que os seus Messias viriam em um futuro imediato (VANDERKAM, 1997, p. 202).

Concluindo, podemos dizer que tinha razão a afirmação do exegeta bíblico W. F. Albright (apud VANDERKAM, 1997, p. 17-19), quando soube da descoberta dos manuscritos: "parabéns pela maior descoberta de manuscritos dos tempos modernos". E em outra ocasião: "é fácil de perceber que esta nova descoberta revolucionará os estudos neotestamentários e logo renderá superados os manuais que tratam do ambiente do NT e da crítica textual e da interpretação do AT”.

\section{Referências}

A BÍBLIA DE JERUSALÉM. São Paulo: Paulus, 2004.

EISENMAN, R; WISE, M. Manoscritti segreti di Qumran. Asti: Piemme, 1994. Edizione italiana a cura di Elio Jucci.

McKENZIE, J. L. Dicionário bíblico. São Paulo: Paulus, 1984.

MARTINEZ, F. G. Textos de Qumran. Tradução de Valmor da Silva. Petrópolis: Vozes, 1995.

VANDERKAM, J. C. Manoscritti del Mar Morto: il dibattito recente oltre le polemiche. Roma: Città Nuova, 1997.

Recebido: $11 / 05 / 2010$

Received: 05/11/2010

Aprovado: 23/07/2010

Approved: 07/23/2010 